\title{
Neuer Alzheimer-Locus nahe dem Tau-Protein-kodierenden Gen entdeckt
}

Fragestellung: Um die Hypothese zu überprüfen, dass die Assoziation von Genloci durch Verwechslung oder Interaktion mit anderen Loci verdeckt sein kann, wurde eine zweistufige genomweite Assoziationsstudie (GWAS) in APOE-Subgruppen durchgeführt.

Hintergrund: Die übliche, sporadische Variante der AlzheimerDemenz (AD) hat eine starke genetische Komponente. Ein guter Teil davon kann durch die bekannten APOE-Genvarianten erklärt werden, die Bestimmung der Genloci spezifischer Proteine und GWAS. Insgesamt erklären die bekannten Gene aber weniger als die Hälfte der erblichen Komponente der Anfälligkeit für die AD und davon macht das APOE-Gen allein 20 - 25\% aus. Weil viele der AD-Genorte an biologischen Prozessen wie Inflammation, Lipidstoffwechsel, Verarbeitung und intrazellulärem Transport von A-beta beteiligt sind, gibt es wahrscheinlich noch mehr AD-Loci.

Jun G, Ibrahim-Verbaas CA Vronskaya $\mathrm{M}$ et al. A novel Alzheimer disease locus located near the gene encoding tau protein. Mol Psychiatry 2016; 21: $108-17$
Patienten und Methodik: Insgesamt wurden in der ersten Stufe 53.711 Individuen rekrutiert, von denen 10.352 APOE\&4-positive Fälle und 9.207 Kontrollen sowie 7.184
APOEع4-negative Fälle und 26.968 Kontrollen analysiert wurden. Dann wurde bei 21.109 SNPs reanalysiert, ob es eine Interaktion mit dem APOEع4-Status gibt. Mögliche Assoziationen wurden in die zweite Stufe mit 4.203 Individuen (1.250 APOE 4 positiv und 536 Kontrollen; 718 APOE\&4-negativ und 1.699 Kontrollen) eingeschlossen.

Ergebnisse: Bei den APOEc4-negativen Personen fanden sich in der Metaanalyse 17 SNP, die alle auf Chromosom 17 in der Nähe des Gens, das für Tauprotein kodiert, liegen. Der SNP mit der höchsten Signifikanz lag in der 100-Kilo-Basenregion, in der auch Tau liegt und das vor allem im Hippocampus, frontalen und temporalen Kortex exprimiert wird. Ansonsten bestätigten sich die bekannten AD-Loci für APOE\&4-positive und -negative Individuen. Weitere SNP zeigten Assoziationen von APOE mit einem Gen, das mit der frontotemporalen Demenz assoziiert ist.

Schlussfolgerungen: Diese genomweite Studie stratifizierte erstmals für die polygene AD ein Gen (APOE), das eine besonders dominante Rolle spielt. Dabei zeigten sich weitere SNP im Chromosom 17. Obwohl die vorliegende Studie mit mehr als 50.000 Teilnehmern gigantisch ist, muss abgewartet werden, ob die Ergebnisse replizierbar sind.

\section{- Kommentar von Markus Weih, Nürnberg}

\section{Hoffen auf APOE- und Tau-basierte Ansätze}

Im Gegensatz zu anderen wichtigen psychischen Krankheiten wie Depression und Psychose, bei denen zumindest einige Fortschritte in der Therapie erkennbar sind, tut sich seit Jahren bei der Alzheimer-Demenz wenig. Es ist daher richtig, sich die Grundlagen noch einmal genauer anzuschauen. Nachdem auch die zahllosen Tiermodelle zwar die Rolle des Amyloidstoffwechsels zeigten, aber therapeutisch nicht den Durchbruch brachten, war es richtig, nicht zu kleckern, sondern zu klotzen und in einer großen Anstrengung ein Konsortium mit mehreren zehntausend Teilnehmern von Kranken und Kontrollen zusammenzustellen und genomweit zu analysieren. Ausgangspunkt war das APOE-Gen, dessen Bedeutung epidemiologisch klar ist, dessen Zusammenhang mit der Pathophysiologie aber weniger. Meist wurde eine modifizierende Rolle beim Amyloidstoffwechsel vermutet. Daher ist das vorliegende Resultat auch überraschend, da mehr ein Zusammenhang von APOE mit dem Tau-Protein nahegelegt wird. Das ergibt Sinn, da die Neurodegeneration und damit die Klinik eher mit der Tau-Pathologie zusammenhängen. Die Ergebnisse stehen auch interessanterweise im Widerspruch zu bisherigen genomweiten Assoziationsstudien mit der Alzheimer-Demenz, die eher ganz andere genetische Grundlagen vermuten ließen. Der derzeitigen Generation von Alzheimer-Kranken werden diese Durchbrüche der Grundlagenwissenschaft aber leider nicht mehr helfen. Sie sind immer noch angewiesen auf Entwicklungen, die mindestens 20 bis 30 Jahre alt sind und nur moderate symptomatische Wirkung entfalten und dazu in Deutschland auch noch vielen Kranken vorenthalten werden. Außer einer interessanten neuen Methodik liefert die vorliegende Studie jedoch neue Hoffnung für APOE- und Tau-basierte Ansätze in der Behandlung der Alzheimer-Demenz.

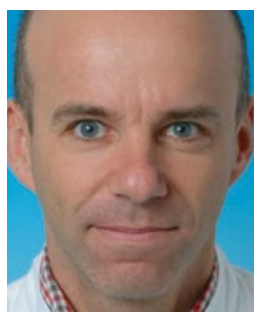

Prof. Dr. med. Markus Weih, Nürnberg

Facharzt für Neurologie, Psychiatrie

und Psychotherapie, Nervenärztliche

Gemeinschaftspraxis

E-Mail:weih@nervenaerzte-

allersbergerstrasse.de 